\title{
De mediações em mediações: a questão da tecnicidade em Martín-Barbero ${ }^{1}$ From mediations to mediations: the question of technicity in Martín-Barbero
}

\author{
LIRÁ UCIO GIRARDI J ÚNIORª \\ Faculdade Cásper Líbero, São Paulo - SP, Brasil \\ Universidade Municipal de São Caetano do Sul, São Caetano do Sul - SP, Brasil
}

\section{RESUMO}

Neste artigo será analisada a virada epistemológica proposta por Martín-Barbero ao deslocar sua atenção das mediações culturais da comunicação para as mediações comunicativas da cultura. $\mathrm{O}$ foco principal da análise estará concentrado na importância que a noção de tecnicidade - ao lado da institucionalidade, da socialidade e da ritualidade - passou a ter em seu pensamento. A sua noção de tecnicidade será tensionada a partir de certas reflexões produzidas pelos estudos das novas mídias e da materialidade da comunicação.

Palavras-chave: Materialidade, mediações, tecnicidade

\begin{abstract}
In this article, we will analyze the epistemological turn proposed by Martín-Barbero when he shifted his attention from the cultural mediations of the communication to the communicative mediations of the culture. The focus of the analysis will be on the importance the notion of technicality - alongside institutionality, sociality, and rituality - had in this epistemological turn. His notion of technicality will be here discussed from certain reflections posed by some studies on new media and materiality of communication.
\end{abstract}

Keywords: Materiality, mediations, technicalities

${ }^{1}$ Versão revisada de trabalho apresentado no Grupo de Pesquisa Teorias da Comunicação, durante o $17^{\circ}$ Encontro dos Grupos de Pesquisas em Comunicação e $40^{\circ}$ Congresso Brasileiro de Ciências da Comunicação, em Curitiba (PR), entre 4 e 9 de setembro de 2017.

${ }^{\text {a }}$ Professor da Faculdade Cásper Líbero e da Universidade Municipal de São Caetano do Sul (USCS). Pesquisador bolsista no Centro Interdisciplinar de Pesquisa (CIP-FCL-2017) e membro do Grupo de Pesquisa Teorias e Processos da Comunicação da Faculdade Cásper Líbero. Orcid: https://orcid.org/00000001-5992-0758. E-mail: girardi@uol.com.br 


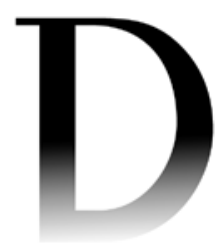

\section{DOS MEIOS ÀS MEDIAÇÕES}

$\mathrm{E}$

M 2017 A obra De los medios a las mediaciones comemorou trinta anos, desde sua publicação em 1987 pela editora Gustavo Gili de Barcelona. A sua tradução e publicação no Brasil esteve sob responsabilidade da editora da Universidade Federal do Rio de Janeiro (UFRJ) e aconteceu em 1997.

Nesses anos, Martín-Barbero tem produzido algumas revisões e tentativas de esclarecimento sobre o que ele entende por mediações e sobre quais seriam os tipos de mediações fundamentais para o entendimento dos processos culturais-comunicacionais (Martín-Barbero, 1995, 2002, 2003, 2006, 2009).

Dos meios às mediações apresenta um primeiro mapeamento daquilo que poderia ser chamado de mediação (Signates, 2006), mas não produz uma reflexão mais aprofundada sobre a própria noção de meio (ver também Bastos, 2008). Nesse projeto fica muito clara a crítica que o autor pretende fazer a uma certa sociologia americana centrada nos efeitos dos meios de comunicação e na chamada teoria da informação de Shannon e Weaver.

Martín-Barbero (1997) procura vincular-se a um projeto iniciado por Walter

${ }^{2}$ No que diz respeito à análise dos meios em Benjamin, Martín-Barbero segue por um caminho que, para o autor deste artigo, é um pouco diferente. Um esboço dessa reflexão pode ser encontrado em Girardi (2017a) e Sá (2004). Benjamin $(1989,1994)^{2}$. A ênfase dada pelo pesquisador às mudanças trazidas pela técnica e seu vínculo com a experiência urbana moderna são incorporados e ampliados para a análise da realidade latino-americana.

A inspiração inicial do seu projeto, Dos meios às mediações, destaca essa complexidade (novas técnicas - metrópole - sensorialidade) de um modo muito claro:

Benjamin se propõe então a tarefa de pensar as mudanças que configuram a modernidade a partir do espaço da percepção, misturando para isso o que se passa nas ruas com o que se passa nas fábricas e nas escuras salas de cinema e na literatura, sobretudo na marginal, na maldita. (Martín-Barbero, 1997: 73)

Nessa primeira fase de seus estudos o pesquisador desloca a atenção, que era dada até então à análise dos meios e seus efeitos, para o processo da recepção. Posteriormente, sob a influência dos debates sobre as chamadas novas mídias, o autor passa a se concentrar cada vez mais no que chama de tecnicidades. Esse movimento, no entanto, procura manter certa coerência com o seu mapa original de análise das mediações, sem nunca se concentrar na própria materialidade da comunicação (Bastos, 2012; Gumbrecht, 2010; Müller, Felinto, 2008).

Em sua obra seminal, o abandono daquilo que chamou de mediacentrismo se fazia necessário pelas próprias circunstâncias históricas da América Latina: as condições históricas e culturais do nosso tipo de desenvolvimento e a força 
dos novos movimentos sociais ${ }^{3}$. A recepção ganha centralidade, mas não sem os riscos de localização desses estudos em uma outra etapa ou momento isolado do processo comunicacional.

Por isso, em vez de fazer a pesquisa a partir da análise das lógicas de produção e recepção, para depois procurar suas relações de imbricação ou enfrentamento, propomos partir das mediações, isto é, dos lugares dos quais provêm as construções que delimitam e configuram a materialidade social e a expressividade cultural da televisão. (Martín-Barbero, 1997: 292)

O próprio pesquisador destaca, então, esse risco e aconselha seus leitores a pensá-lo como uma espécie de "reencontro dos estudos da comunicação com a sociedade latino-americana de hoje" (Martín-Barbero, 1995: 39), em uma ruptura com uma epistemologia condutivista e mecânica da comunicação, centrada apenas na emissão e na ausência de verdadeiros intercâmbios entre verdadeiros atores. Nessa primeira etapa de seu trabalho, ele desenvolve o que chamou de mediações culturais da comunicação - o esboço de um primeiro mapa noturno de exploração das mediações ${ }^{4}$.

Esse novo lugar passa a ter uma importância fundamental no processo de reflexão sobre o vínculo entre as práticas culturais e os processos comunicacionais que as orientam, pois "não é somente uma etapa no interior do processo de comunicação, um momento separável, em termos de disciplina, de metodologia, mas uma espécie de um outro lugar, o de rever e repensar o processo inteiro da comunicação" (Ibid.: 40).

As possibilidades de análise abertas pela interpretação de sua obra, no entanto, fazem com que Martín-Barbero seja obrigado a esclarecer algumas questões. Torna-se cada vez mais importante destacar que essa mudança do lugar em que se produz a relação entre comunicação, política e cultura nas sociedades latino-americanas não deve levar à falsa impressão de que as pessoas podem fazer o que quiserem com os bens culturais. Deve ficar claro que a capacidade que os atores têm de se apropriar desses bens e do mundo em que vivem envolve condicionamentos históricos, sociais, políticos e culturais muito particulares.

A ideia de que "temos de estudar não o que fazem os meios com as pessoas, mas o que fazem as pessoas com elas mesmas, o que elas fazem com os meios, sua leitura" (Ibid.: 55) não deve, como já foi dito, transformar a recepção em uma etapa destacada e autônoma da pesquisa. É preciso entender como a mediação passa a ser a articuladora da compreensão das lógicas de produção e seus formatos industriais no encontro com as matrizes culturais e as práticas de consumo dos usuários. Essas seriam as mediações culturais da comunicação.
${ }^{3}$ Sobre as tendências latinoamericanas nos estudos de recepção, ver Jacks (1996).

4 "Y fue ese artesanal oficio el que guió la larga, cerca de diez años, investigación que recogió De los medios a las mediaciones, donde sinteticé así lo que entendía por mapa nocturno: un mapa para indagar la dominación, la producción y el trabajo pero desde el otro lado: el de las brechas, el consumo y el placer" (Martín-Barbero, 2002: 16, destaque nosso). 




${ }^{5}$ Um procedimento que não escapa a Walter Benjamin (1994).

6"Jesus Martín-Barbero é um autor fundamental para a construção de uma nova abordagem dos gêneros televisivos, em razão de seu esforço de pensar modelos comunicativos que abarquem a totalidade do processo, por sua concepção de gênero como estratégia de comunicabilidade e por considerar o caráter contingente e transitório do gênero e as distintas temporalidades que ele convoca. Além do mais, ele investiga a televisão, toma o gênero televisivo como uma categoria cultural, adota uma abordagem fortemente historicizada e nos oferece pistas para pensar os vínculos entre comunicação, cultura, política e sociedade" (Gomes,

2011: 113).

${ }^{7} \mathrm{Na}$ discussão que está sendo proposta neste artigo, a respeito da tecnicidade em MartínBarbero, é importante destacar que, para Manovich (2001), a presença das novas mídias traz um elemento novo para a análise das mediações e sua relação com a comunicação.

Nas novas mídias lida-se não apenas com a camada cultural (da qual os gêneros são a mediação principal), mas também com sua materialidade muito particular, a camada computacional (ver: Girardi, 2017b).

Nesse ponto o autor fala da lógica capitalista de produção de bens culturais - de uma lógica industrial orientando a produção simbólica nos meios de comunicação - mas não toca em nenhum momento na própria materialidade dos meios sociotécnicos como parte de um tipo específico de mediação ${ }^{5}$. Algumas vezes, a sua proposta vê nos gêneros a possibilidade de articulação entre lógicas e práticas de produção e lógicas e práticas de recepção $0^{6}$.

Entre a lógica do sistema produtivo e as lógicas dos usos, medeiam os gêneros. São suas regras que configuram basicamente os formatos, e nestes se ancora o reconhecimento cultural dos grupos. [...] No sentido em que estamos trabalhando, um gênero não é algo que ocorra no texto, mas sim pelo texto, pois é menos questão de estrutura e combinatórias do que de competência. Assumimos então a proposta de uma equipe de investigadores italianos segundo a qual um gênero é, antes de tudo, uma estratégia de comunicabilidade. (Martín-Barbero, 1997: 301-302)7

\section{A ANÁLISE DAS MEDIAÇÕES NO FOLHETIM}

Ao falar do aparecimento do folhetim, Martín-Barbero (1997) descreve como as mediações relacionadas às lógicas de produção, aos formatos industriais, às matrizes culturais e às competências da recepção (consumo) articulam-se.

$\mathrm{Na}$ existência de um mercado de bens simbólicos orientado por uma lógica capitalista, esse formato industrial - que encontra seu lugar, em um primeiro momento, no jornal - marca o aparecimento de uma nova lógica da produção: a relação entre o editor e o autor, e a mudança da relação do escritor com o seu próprio processo criativo. Isso se manifesta:

1. na relação assalariada que o autor do folhetim estabelece com a organização jornalística;

2. no ritmo da produção que o faz escrever sob pressão de uma periodicidade muito particular desses formatos - o que o força a escrever contra o relógio;

3. no modo de escrita que obrigou o escritor a se adequar a uma forma de construção narrativa muito peculiar.

Esses novos ambientes comunicacionais pressupõem mediações específicas. Uma delas é a "mediação institucional com o mercado que orienta, rearticula a intencionalidade 'artística' do escritor" (Ibid.: 175), que passa a ser avaliada em termos de produtividade e rentabilidade e que enfatiza mais as particularidades do gênero do que o estilo do próprio autor.

Além disso, as dinâmicas e os circuitos de consumo que envolvem o jornal são muito diferentes daquelas que envolvem um livro, por exemplo. Em um 
primeiro momento, o folhetim, em sua materialidade e institucionalidade, não assumirá o estatuto cultural do livro. Sua existência se vincula à forma-jornal e a tudo o que ela representa em termos de lógica de produção e consumo: sua temporalidade e ritualidade ${ }^{8}$.

A alteração nos modos de aquisição (venda em banca, assinatura semanal ou diária) e a forte presença da propaganda, fatores que caracterizam as produções jornalísticas na ordem capitalista moderna, vão produzir também um novo tipo de mediação entre o mercado e as práticas culturais.

Ao falar do famoso folhetim de Eugène Sue, Os mistérios de Paris, MartínBarbero (1997) observa como a participação dos leitores, por meio de cartas ao jornal, era intensa. As cartas criticavam, por um lado, a dureza com que Sue relatava a vida de suas personagens e, por outro, até mesmo o tom socialista do seu folhetim. Alguns acreditavam que as personagens que apareciam nas narrativas eram reais, e esses tipos ficcionais passaram a servir de referência, sendo incorporados pelos próprios leitores das classes populares.

Entretanto, como observa o autor, não se deve passar "das estruturas dos textos às da sociedade ou vice-versa, sem passar pela mediação constituidora da leitura. Da leitura viva, isto é, daquela que as pessoas fazem a partir de sua vida e dos movimentos sociais em que a vida se vê enredada" (Ibid.: 179).

Essas mediações entre lógica da produção/formatos industriais e matrizes culturais/competências de recepção deixam suas marcas no texto. Uma nova materialidade instaura-se também. Ela pode ser vista nos dispositivos de composição tipográfica (letras grandes e espacejadas), que procuram tornar agradável e fácil a leitura a usuários acostumados à cultura oral. Era preciso provocar o desejo da leitura a partir de interesses comerciais muito claros (Ibid.: 180).

$\mathrm{Na}$ articulação entre a lógica da produção/formatos industriais e as matrizes culturais/competências de recepção, são desenvolvidos dispositivos de fragmentação da leitura, como uma nova organização da narrativa (baseada em episódios, capítulos, subcapítulos). Eles são acompanhados de certos dispositivos de sedução: o encadeamento dessas fragmentações em uma duração específica e organizada segundo a lógica do suspense - em constante negociação com seu público leitor permitindo que a narrativa seja incorporada ao ritmo da vida cotidiana (Ibid.: 181).

A estrutura aberta permite a sua atualização, uma negociação constante, um jogo de sedução a partir de certas regras que envolvem um equilíbrio criativo entre surpresas e repetições. Não é mais, propriamente, sobre o autor dos folhetins que recai a legitimidade institucional da criação. Ela é transferida ao gênero, torna-se uma espécie de narrativa estandardizada de gênero.

Esse processo se completa com os dispositivos de reconhecimento. Nessas narrativas o leitor reconhece a sua realidade cotidiana, na medida em que
${ }^{8}$ Sobre a materialidade e os formatos industriais na diferença entre o jornal (a crônica) e o livro, ver o capítulo "A crônica cinematográfica" da obra João do Rio e seus cinematógrafos, de Aline da Silva Novaes (2015). 
encontra um tipo particular de herói que não tem mais nada de sobrenatural: as personagens são pessoas como nós!

As questões éticas e estéticas estão diretamente relacionadas na trama - uma espécie de moral da história que articula a experiência de violência, de medo e de ressentimento, de um lado, à da esperança de revanche e de vingança, de outro (Ibid.: 184).

Esse conjunto de mediações chega a um grau de amadurecimento que acaba por libertar o folhetim da materialidade do jornal. Nessa nova lógica de institucionalização -na forma-livro - ele passa a ter um circuito próprio de produção, consumo e avaliação de sua legitimidade cultural.

É preciso lembrar também que, antes de se tornar parte da ritualidade e socialidade cotidiana, essa nova experiência cultural urbana teve de ser aprendida - retomando uma inspiração benjaminiana. Ela não dependia apenas de um processo massivo de alfabetização, mas da incorporação de uma nova forma cultural (Williams, 2016) - uma mediação institucional do mercado sobre os formatos industriais urbanos, nas suas relações com as matrizes culturais e as novas competências cognitivas negociadas entre produtores e consumidores desses bens.

A sua institucionalidade se torna o espaço de disputas hegemônicas em torno das formas e dos sentidos da produção simbólica em uma sociedade marcada pela divisão de classes e pelas relações de mercado. Mas não se trata exclusivamente da submissão a uma lógica mercantil ou a uma ideologia dominante pura e simplesmente.

Estamos afirmando que as modalidades de comunicação que neles e com eles aparecem só foram possíveis na medida em que a tecnologia materializou mudanças que, a partir da vida social, davam sentido a novas relações e novos usos. Estamos situando os meios no âmbito das mediações, isto é, num processo de transformação cultural que não se inicia nem surge através deles, mas no qual eles passarão a desempenhar um papel importante a partir de um certo momento - os

${ }^{9}$ Um dos propósitos deste artigo é dar início a uma série de reflexões sobre a relação entre a teoria das mediações e as chamadas cultural techniques ou, dito de outro modo, sobre como a ideia de mediações pode ser introduzida nos estudos sobre a materialidade da comunicação. anos vinte. (Ibid.: 191) ${ }^{9}$

\section{O LUGAR DAS MEDIAÇÕES}

Martín-Barbero, ao lado dos representantes dos estudos culturais (Hoggart, 1973; Williams, 2016) e de outros pesquisadores latino-americanos, como Orozco Gómez (2005), procura redefinir aquilo que está realmente em jogo nas práticas comunicativas. Já foi visto que o pesquisador se distancia da teoria dos efeitos e do chamado mediacentrismo, mas é preciso ressaltar também que 
Martín-Barbero procura se distanciar daquilo que ele mesmo chama de abordagem culturalista $^{10}$ : "O desafio apresentado pela indústria cultural aparece com toda a sua densidade no cruzamento dessas duas linhas de renovação que inscrevem a questão cultural no interior do político e a comunicação, na cultura" (Martín-Barbero, 1997: 287).

Para entender essa nova postura, ele identifica três lugares fundamentais de análise das mediações, que estão relacionados às experiências dos usuários com os meios eletrônicos de comunicação, basicamente o broadcasting:

1. cotidianidade familiar - a vida familiar passa a ser o lugar em que a experiência de recepção ocorre. Isso marca as instâncias de produção, capazes de simular presença e proximidade, uma relação de contato à distância que aparece na figura do apresentador-animador e no modo pelo qual interpela sua audiência - um discurso que familiariza tudo, desde os acontecimentos até as personagens das histórias;

2. temporalidade social - é marcada pela articulação entre a grade de programas/gêneros e os rituais do ambiente doméstico, marcados por um determinado tipo de rotina;

3. competência cultural - uma espécie de letramento audiovisual orientado por uma produção cultural serial e pela divisão dos produtos/gêneros audiovisuais na grade de programação. Um jogo de repetição, reconhecimento e novidade com relação às narrativas ${ }^{11}$.

Todos esses lugares são marcados por uma série de diferenças nas condições sociais e culturais dos atores. Por isso, é preciso entender como o habitus de classe ou dos grupos sociais tem um papel importante na avaliação dos tipos de recursos/capitais que serão ativados pelos sujeitos, e as formas assumidas por essas mediações.

No modelo das múltiplas mediaçães, proposto por Orozco Gómez (2005), há um desdobramento e uma configuração mais ampla dos tipos de mediações que podem ser identificadas e estudadas. São elas:

1. referenciais: dependem de valores e da história familiar, do nível educacional, dos repertórios culturais, das relações de classe, gênero, idade e etnia;

2. cognitivas: ocorrem por meio dos scripts, espécies de roteiros mentais que indicam enquadramentos e relevância cultural de determinados temas, situações e modos de percepção (modos específicos de leitura) postos em negociação na comunicação;

3. situacionais: envolvem um tipo de relação específica com os meios, ligada ao tipo de espaço em que esse encontro ocorre, a forma pela qual esses meios disputam a atenção de seus usuários (que podem
${ }^{10}$ Sobre a identificação do autor como representante de uma abordagem culturalista, ver: Bastos (2008); Dalmonte (2002); Temer, Tondato (2014).

${ }^{11}$ Martín-Barbero observa como essa competência cultural é vista de um modo muito particular no mundo da arte: praticamente não existem listas de obras clássicas da televisão, o máximo que se pode encontrar são almanaques. Esse é o mesmo questionamento feito por Machado (2000). 
estar sozinhos, reunidos na sala ou realizando outras atividades, enquanto a televisão ocupa o lugar de um ruído de fundo, por exemplo, um tipo de atenção distraída);

4. institucionais: têm por base o fato de que a televisão se transformou em uma instituição social produtora de significados, por intermédio da qual o espectador é envolvido por um conjunto de agenciamentos em concorrência com outras instituições (família, escola, trabalho) e seus agenciamentos particulares;

5. videotecnológicas: tendo em vista que os meios têm uma dinâmica própria de produção de representações e modos particulares de interpelar seus usuários, essas mediações passam pelos gêneros midiáticos e por sua maior ou menor função denotativa, considerando o apagamento dos processos e códigos de produção - a sua naturalização.

Uma observação importante de Orozco Gómez sobre as mediações é que elas podem ser articuladas de modo complexo, mobilizando rituais, rotinas, reconhecimentos e afetos. Essas mediações assumem configurações muito particulares, sobrepondo-se ou até mesmo se anulando.

O pesquisador observa também que as comunidades de apropriação - os locais em que se tem a experiência direta com esses bens culturais, como o ambiente doméstico - nem sempre coincidem com as comunidades de interpretação - outras esferas de negociação de sentido sobre essa mesma experiência, que podem ser o trabalho, a escola etc. (Girardi, 2009). Conforme Orozco Gómez,

Três premissas básicas orientam a análise da recepção televisiva. Primeira, que a recepção é interação; segunda, que essa interação está necessariamente mediada de múltiplas maneiras; e terceira, que essa interação não está circunscrita ao momento de estar vendo a tela. O objeto de estudo, por conseguinte, serão as diversas mediações ao "longo e amplo" processo de recepção. (2005: 37)

Retomando uma análise histórica desse processo e procurando identificar como o broadcasting assume uma forma cultural específica (novas técnicas metrópole - sensorialidade), Williams (2016) observa que a experiência com os meios audiovisuais é construída no interior de um conjunto de transformações do mundo moderno: urbanização, aumento de salários, expansão do tempo livre e da mobilidade, ampliação de tecnologias públicas de eletrificação, transporte etc.

Ao lado do aumento de mobilidade produzido na modernidade, um processo muito particular, aparentemente paradoxal, ocorre: a construção de um tipo de experiência baseada em meios de comunicação centrados no lar - uma série de tecnologias domésticas (Mackay, 1997; Morley, Silverstone, 1990). Esses 
meios podem assumir a forma de jornais, revistas, catálogos, rádios e televisores que passam a ocupar um lugar específico no interior da vida familiar. Williams identificará esse tipo de experiência como uma forma de mobilidade privatizada.

É importante notar a convergência teórica que se desenvolve entre a teoria das mediações e as novas gerações dos estudos culturais, particularmente, com os trabalhos de Morley (1992) e Silverstone (1991), concentrados na construção das chamadas "tecnologias domésticas" e de uma nova "economia moral" centrada na família. Esses estudos mostram que o ambiente comunicacional produzido pela televisão é tanto tecnológico como social e que as mediações, nele presentes, devem ser avaliadas com bastante cuidado como uma série de práticas culturais rotinizadas e ritualizadas. (Girardi, 2009: $123-124)^{12}$

\section{O LUGAR DA TECNICIDADE}

Boa parte das análises de Martín-Barbero sobre as mediações estava relacionada aos usos do broadcasting ou, em particular, à televisão. O desenvolvimento e a expansão das chamadas novas mídias, da convergência digital e das tecnologias móveis, aliadas à possibilidade de fruição de bens culturais em múltiplas telas e ambientes, além da interatividade, e a associação desses elementos a uma nova dinâmica cultural globalizada fizeram com que Martín-Barbero procurasse dar maior atenção àquilo que chamou de tecnicidade - um tipo novo e particular de mediação ${ }^{13}$.

Embora esse novo ambiente comunicacional tenha passado a demandar profunda atenção, Orozco Gómez (2006) avalia que se faz necessária uma série de cuidados em sua análise. Por exemplo:

1. é preciso lembrar que um novo meio ou tecnologia não substitui imediatamente um meio anterior;

2. novas tecnologias demandam tempo de aprendizagem e de apropriação por parte dos usuários - novos letramentos;

3. as tecnologias (novas ou não) demandam tipos de atenção e experiências diferenciadas, o que pode retardar a transição de uma para outra;

4. é bem possível que as novas tecnologias móveis atendam melhor a determinadas demandas de seus usuários do que as tecnologias anteriores. No entanto, elas não atendem a todas as necessidades, o que abre espaço para uma recomposição das antigas mídias;

5. os usuários precisam produzir uma série de ajustes em suas experiências cotidianas para incorporá-las;
${ }^{12}$ Esse quadro tem mudado aceleradamente a partir da expansão dos dispositivos móveis e das redes wifi, $3 \mathrm{G}$, $4 \mathrm{G}$ etc., criando um ambiente comunicacional e um quadro de mediações bastante complexo (Girardi, 2009).

${ }^{13}$ Uma importante reflexão sobre a relação entre novos tipos de mediações e as novas mídias pode ser encontrada em Vaz (2001). 


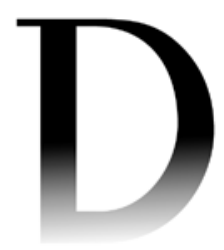

${ }^{14} \mathrm{Um}$ dos desafios para MartínBarbero seria enfrentar esta observação de Gunkel (2009: 53): "o computador, apesar de tudo o que lemos sobre os novos meios, a convergência de mídia e isso e aquilo digital, não é nem uma nova forma de comunicação; uma elaboração, continuação e confluência prévia de tecnologias de mídia; nem uma nova ferramenta no arsenal de produção e distribuição de mídia. Em vez disso, ele constitui o fim da mídia como nós a conhecíamos. Em outras palavras, o computador marca o fim não apenas de uma forma particular de mídia, como com frequência defendem os acadêmicos da alfabetização e dos estudos de mídia [refere-se a Bolter, Grusin, McLuhan e Ong], mas de um conceito particular e paradigmático da mídia enquanto tal". No original: "the computer, despite everything we now read about new media, media convergence, and digital this and that, is neither a new form of mediated communication; an elaboration, continuation, and confluence of previous media technologies; nor a new tool in the arsenal of media production and distribution. Instead it constitutes the end of media as we have known it. In other word, the computer marks the end not just of a particular form of media, as has often been argued by scholars of both literacy and media studies [...], but of a particular and paradigmatic concept of media such". Tradução minha.
6. elas têm um custo nada desprezível para muitos usuários, o que pode afetar o processo de migração tecnológica.

Para Orozco Gómez, a experiência com as novas tecnologias móveis não produz apenas um desordenamento do ambiente comunicacional anterior e de suas mediações, mas tipos particulares de recomposição.

Uma mudança (sócio) cultural supõe então uma mudança de sedimentações na produção simbólica (que requer seu tempo) [...]. Destempos que supõem ajustes e processos de aprendizagem substantivos por parte dos atores sociais, e que quase sempre acabam inconclusos. (Orozco Gómez, 2006: 86)

Foi diante desse quadro complexo que Martín-Barbero (2002, 2006, 2009) se viu, de algum modo, obrigado a enfrentar uma questão: o que acontece com a cultura e a sociedade quando as novas mídias deixam de ocupar uma posição apenas instrumental e passam a ampliar e intensificar os espaços/tempos em que a comunicação pode "espessar-se, condensar-se e converter-se em estrutural" (Martín-Barbero, 2006: 54)?

Como ser o cartógrafo de mediações comunicativas com esse grau de fluidez? Como configurar as próprias questões que merecem ser pensadas, mapeadas e exploradas? Quais são as diversas pistas de penetração nessas múltiplas temporalidades, seus "destempos” e suas “desmemórias" (MartínBarbero, 2002: 2-3)?

$\mathrm{Na}$ busca por essas respostas-explorações, o pesquisador destaca que o computador não é uma máquina tradicional de produção de objetos simbólicos, mas a portadora de um novo tipo de tecnicidade que se constitui pelo processamento de informações ou dados. Sua matéria-prima são abstrações e símbolos. O código numérico passa a ser um dos mediadores universais da produção simbólica sob essa nova tecnicidade:

Estamos diante da emergência de uma "nova figura da razão" que exige pensar a imagem, por um lado, desde sua nova configuração sociotécnica [...] e, por outro, a emergência de um novo paradigma do pensamento, que refaz as relações entre a ordem do discursivo (lógica) e a do visível (a forma), da inteligibilidade e a sensibilidade. (Martín-Barbero, 2006: 73)

Embora a citação direcione a atenção do leitor para uma espécie de mediação relacionada à materialidade da comunicação, o seu desenvolvimento cai novamente na questão dos gêneros e nas possibilidades da produção simbólica ${ }^{14}$. O que o surpreende, no caso, é o significado do hipertexto e a forma reticular 
assumida pelas redes sociotécnicas. Essa seria a sua tecnicidade: os novos campos da experiência, das linguagens e da sensorialidade humana.

Em seus primeiros mapas o autor se concentrava nos lugares das mediações, representados pela cotidianidade familiar, pela temporalidade social e pela competência cultural, como já visto. Esse modelo foi representado como um diagrama composto por um eixo horizontal - que identifica a relação entre as mediações culturais, de um lado, e os formatos industriais, de outro - e um eixo vertical - que relaciona a lógica da produção industrial capitalista e a competência de recepção do usuário. Por meio desse mapa das mediações culturais da comunicação seriam pensadas as articulações entre comunicação, cultura e política (Martín-Barbero, 2009).

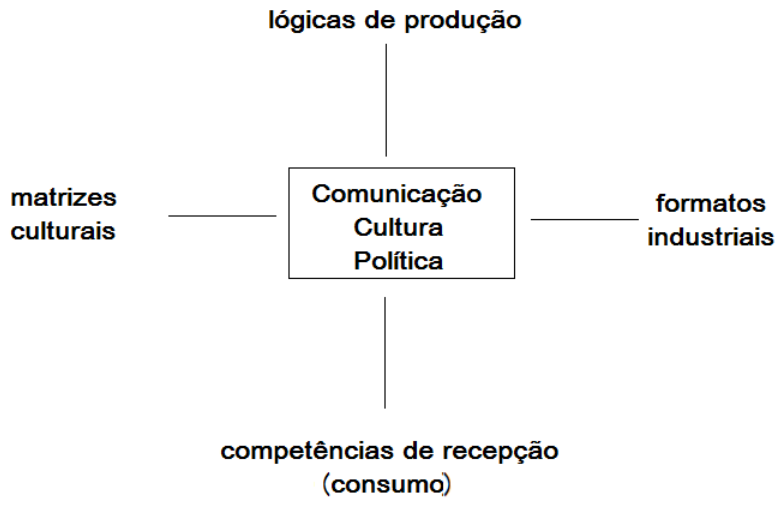

FIGURA 1 - Primeiro mapa das mediações culturais da comunicação

No prefácio à quinta edição da sua obra De los medios a las mediaciones, Martín-Barbero observa que naquele momento estava produzindo uma espécie de mapa noturno de identificação e localização das mediações.

No entanto, a partir de um seminário organizado por Orozco Gómez, referente aos usos dos meios e às práticas comunicativas, Martín-Barbero desloca sua análise para o que chamou de mediações comunicativas da cultura.

Inverto meu primeiro mapa e proponho as "mediações comunicativas da cultura", que são: a "tecnicidade"; a "institucionalidade" crescente dos meios como instituições sociais e não apenas aparatos, instituições de peso econômico, político, cultural; a "socialidade" - como o laço social está se transformando para os jovens, como as relações entre pais e filhos, e entre casais, estão mudando. [...] E, finalmente, as novas "ritualidades" que acontecem em relação aos novos formatos industriais possibilitados pela tecnicidade. (Martín-Barbero, 2009: 152) 


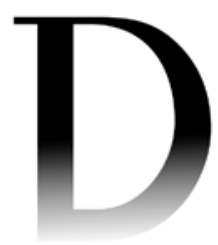

${ }^{15}$ Couldry (2016) e Couldry e Hepp (2017) falam em ondas de midiatização, midiatização profunda, media manifold (a complexa rede de plataformas de produção, compartilhamento e acesso a conteúdos), mas a visão desses autores sobre a materialidade segue a mesma lógica adotada por Martín-Barbero: "O mundo social não é simplesmente um dado. Nós o construímos, como seres humanos, nesse sentido, é socialmente construído [...]. De fato, requer insistir que o social é material, uma materialidade que não é 'um estrato previamente dado', no qual os seres humanos estão inseridos, mas um produto da própria interação humana, com todas as suas relações de poder e desigualdades" (Couldry; Hepp, 2017). No original: “The social world is not just a given. We make it, as human beings; it is, in this sense, socially constructed [...]. Indeed it involves insisting that the social is material, a materiality that is not a 'pre-given' stratum into which human beings are inserted, but a product of human interaction itself, with all its power-relations and inequalities". Tradução minha. O mesmo ocorre com Scolari (2015) ao destacar que da mesma forma que MartínBarbero passou dos meios às mediações, seria preciso ir, agora, das novas mídias às hipermediações.
Como observa Lopes (2014), o autor parecia estar fortemente pressionado a fazer um movimento inverso àquele proposto em sua obra seminal.

Tratava-se, agora, de retomar "antigas questões"? Não seria o caso de um novo deslocamento das mediações para os meios a fim de compensar, assim, um certo desequilíbrio na análise dos ambientes comunicacionais e suas mediações?

No entanto, Martín-Barbero resiste sensivelmente a seguir esse caminho. Ele aceita mudar o "lugar a partir do qual estava olhando", mas deixa bem claro que isso não significa "assumir a prioridade dos meios", e sim reconhecer que "o comunicativo está se transformando em protagonista de uma maneira muito mais forte" e que a comunicação "se adensa" na era da nova tecnicidade (Martín-Barbero, 2009: 152) ${ }^{15}$.

Sendo assim, nesse novo ambiente sociocomunicativo a abordagem deveria concentrar-se no que ele chamou de mediações comunicativas da cultura: a ritualidade, a institucionalidade, a socialidade e a tecnicidade (Gomes, 2011; Lopes, 2014; Martín-Barbero, 2009; Ronsini, 2010; Sifuentes, Escosteguy, 2016; Silva, 2012).

Um diagrama complementar é proposto, no qual se introduz um tipo novo de mediação que, até então, não parecia ter o destaque adequado no pensamento de Martín-Barbero: a tecnicidade. A proposta de interlocução com a materialidade da comunicação e o estudo das novas mídias passa por essa abertura encontrada no novo diagrama da teoria das mediações (Martín-Barbero, 2003: 16).

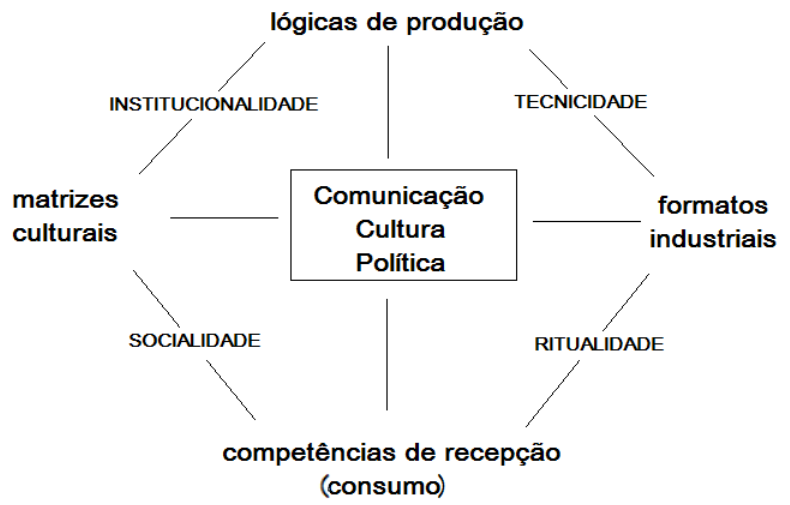

FIGURA 2 - Mapa das mediações comunicacionais da cultura

Hjarvard (2012, 2015), a seu modo, parece reconhecer a mesma institucionalização das novas formações midiáticas como um fator fundamental para análise do mundo contemporâneo: "Ao aplicar uma perspectiva institucional, é 
importante considerar como podemos pensar as diversas mídias - particularmente as novas mídias - como instituições" (Hjarvard, 2015: 56).

Nenhuma das teorias da mediação ou da midiatização ${ }^{16}$ se concentra nas materialidades particulares que caracterizam essas novas mídias, nem procura explicar de que forma elas abrem um campo de possíveis para suas formas de institucionalização e usos ${ }^{17}$.

Por isso, caberiam algumas questões: a própria materialidade dos meios não estaria relacionada a certos tipos de mediação específicos? Martín-Barbero não deveria explicar, de alguma forma, o que há de novo nessas novas mídias - que possibilitam um adensamento da comunicação - e como isso cria condições para uma mudança qualitativa em sua análise das mediações?

Fica muito claro que a recusa do autor em deslocar suas reflexões das mediações para os meios é coerente com sua proposta inicial. Em seu pensamento, as mediações são da ordem das "dimensões simbólicas da construção do coletivo" (Martín-Barbero, 2009: 151), portanto, o lugar da materialidade das novas mídias não aparece, a não ser de forma indireta, como parte da experiência simbólica ${ }^{18}$.

Essa posição, a seu modo, também pode ser encontrada na proposta de Hjarvard, ao argumentar que as novas práticas e formas de expressão, os gêneros e formatos nas novas mídias não podem ser reduzidos simplesmente à existência do código binário. As novas performances comunicativas devem ser pensadas a partir de uma perspectiva institucional em meio à qual articulam sua existência cotidiana e social ${ }^{19}$.

Notícias, narrativas audiovisuais e redes sociais são influenciadas pela digitalização, mas são também gêneros comunicativos ou formatos de mídia de uma ordem superior e possuem uma estrutura própria. Tais características não podem ser reduzidas à sua composição binária elementar. Mídia e gêneros são ao mesmo tempo formatos comunicativos com affordances particulares e formas institucionalizadas de interação social. (Hjarvard, 2015: 55)

Isso fica claro também em Martín-Barbero (2009: 153), ao destacar que nas mediações comunicacionais da cultura a "noção de comunicação sai do paradigma da engenharia e se liga com as 'interfaces', com os 'nós' das interações, com a comunicação-interação, com a comunicação intermediada”.

Essa intermedialidade faz diferença para o autor. Ela não é análoga a uma nova forma de intertextualidade - uma relação entre textos que já existem -, mas a uma contaminação entre sons, textos, imagens - as matérias-primas dos gêneros narrativos - que demanda uma nova ordem de conhecimentos e
${ }^{16}$ É possível dizer que as relações entre mediação e midiatização assumem uma forma complexa para Livingstone (2009), Hepp (2014) e Hjarvard (2015). As dificuldades quanto ao seu entendimento se referem a questões tanto semânticas quanto históricas e conceituais: "Discussões internacionais recentes apontam para a resolução destas discordâncias terminológicas em favor da distinção europeia continental entre 'midiatização' (denotando a dimensão estrutural de longo prazo) e 'mediação' (significando o uso da mídia em encontros comunicativos)" (Hjarvard, 2015: 53). Entretanto, é importante destacar novamente que nenhuma delas coloca em destaque as mediações que envolvem a própria materialidade das mídias.

${ }^{17}$ Essa postura pode ser encontrada em Finnemann (2011), que, inspirado em Meyrowitz (1985), identifica cinco matrizes midiáticas capazes de orientar a análise dos meios e das mediações (termo não usado pelos autores). Trata-se de sociedades articuladas pela predominância: da oralidade; da escrita; das formas impressas; das mídias eletrônicas analógicas; e das mídias digitais. Cada uma delas pode ser caracterizada pela particular orientação ou reorientação das percepções de tempo e espaço, dos seus modos específicos de armazenamento, reprodução e distribuição e dos possíveis repertórios perceptivos e semióticos que possibilitam. O significado de qualquer meio só pode ser encontrado no interior dessa matriz e das institucionalizações específicas que é capaz de ajudar a produzir. Nesse caso, a particularidade das mídias digitais - sua tecnicidade como articuladora da nova matriz - tem consequências muito claras para o entendimento das condições de socialidade, institucionalidade e ritualidade. 


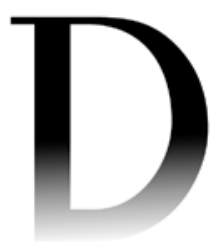

${ }^{18}$ É o que pode ser visto também nas tentativas bastante sofisticadas de depuração desse projeto: "Minha proposta não é substituir um modelo pelo outro, mas tentar articular os dois sem perder de vista as bases do modelo anterior que se assentava em lógicas da produção, lógicas da recepção, matrizes culturais e formatos industriais que são mais explanatórias do que as categorias tempos, espaços, migrações e fluxos. Em meu entendimento, identidades e cognitividades podem ser noções embutidas tanto na mediação da socialidade quanto da ritualidade e o conceito de tecnicidade adquire um novo estatuto para além de mediar a relação entre as lógicas da produção e formatos industriais. Portanto, a tecnicidade pode ser compreendida em sentido estrito, como o aspecto textual, narrativo ou discursivo da mídia que funciona como organizador perceptivo" (Ronsini, 2010: 7).

${ }^{19}$ Braga observa que "não se trata de retornar das mediações aos meios: ambos são parte necessária e significativa da abrangência que nos interessa.

Mas ao mesmo tempo, não são objetos suficientes". Depois complementa: "Essas práticas, esses processos, em toda sua variedade, tornam-se objeto possível para nossa investigação - desde que, de algum modo, produzam ação interacional" (2012: 37).

20 "Elaborei então um documento para defender, até no Ministério da Educação, a transdisciplinaridade entre filosofia, história, estudos da linguagem e literatura. [...] Mas as origens da transdisciplinaridade remetem ao ano de 1944, um pouco antes de terminar a guerra mundial, no MIT, quando se reúnem, com Norbert Wiener, um neuropsicólogo, Arthur Rosenfeld; um psicólogo, Kurt Lewin; e um competências baseadas na transdisciplinaridade ${ }^{20}$ e novas formas de convergência. Sua análise é relevante, mas em nenhum momento essa intermedialidade é vista a partir da materialidade da comunicação. Esse posicionamento não tem um lugar específico na teoria de Martín-Barbero.

Para Hjarvard, entretanto, essa questão merece um pouco mais de atenção. Na perspectiva do autor, a materialidade da comunicação (e suas affordances) limita algumas das formas possíveis de usos sociais das novas mídias $^{21}$.

O que preocupa Martín-Barbero é o risco de pensar esse "adensamento tecnológico-comunicacional" sob a ótica de um determinismo tecnológico ou pela análise mecânica de seus efeitos sobre a vida social. Existiria um risco, ainda, de se render a um discurso que associa certo otimismo tecnológico a um profundo pessimismo político, orientado pela onipresença e pela inevitabilidade da lógica do mercado (Martín-Barbero, 2003).

São alertas relevantes, mas existem formas de escapar dessas armadilhas e propor novas direções para esse debate.

\section{CONSIDERAÇÕES FINAIS}

O objetivo deste artigo foi resgatar alguns dos esforços seminais de MartínBarbero na construção de uma teoria das mediações e tensioná-la ${ }^{22} \mathrm{em}$ seu estágio atual rumo a uma interlocução com os estudos sobre as novas mídias e a materialidade da comunicação.

Nesse sentido, entender a comunicação, a cultura e a política a partir de mediações como institucionalidade, socialidade, ritualidade e tecnicidade torna-se epistemologicamente relevante para os estudos de comunicação. No entanto, a análise dessa tecnicidade como mediação comunicacional da cultura deveria levar em conta também a construção das próprias arquiteturas comunicacionais rumo a uma materialidade dos possíveis ${ }^{23}$.

A opção de articular comunicação, cultura e política não deveria passar pelas mediações que envolvem essa materialidade das formações comunicativas ${ }^{24}$ ?

Embora a teoria das mediações tenha um legado intelectual e histórico indiscutível, a noção de tecnicidade proposta por Martín-Barbero em seus últimos trabalhos abre espaço para uma interlocução enriquecedora com as teorias citadas.

Na busca por essa interlocução, o caminho proposto para o debate não consiste tanto em ir dos meios às mediações ou das mediações aos meios, mas de mediações em mediações, para que seja possível identificar as diversas configurações ou formações comunicacionais da cultura. $\mathbf{M}$ 
REFERÊNCIAS

BASTOS, M. T. Do sentido da mediação: às margens do pensamento de Jesús Martín-Barbero. Revista Famecos, Porto Alegre, n. 35, p. 86-89, abr. 2008. DOI: http://dx.doi.org/10.15448/1980-3729.2008.35.4096 Medium, media, mediação e midiatização: a perspectiva germânica. In: JANOTTI Jr., J.; MATTOS, M. Â.; JACKS, N. (Orgs). Mediação \& Midiatização. Salvador: Edufba; Brasília: Compós, 2012. p. 53-77.

BENJAMIN, W. Sobre alguns temas em Charles Baudelaire. In: . Charles

Baudelaire: um lírico no auge do capitalismo. São Paulo: Brasiliense, 1989. p. 9-101. (Obras Escolhidas, v. 3).

A obra de arte na época de sua reprodutibilidade técnica. In:

Magia e técnica, arte e política: ensaios de literatura e história da cultura. São Paulo: Brasiliense, 1994. p. 165-196. (Obras Escolhidas v. 1).

BOURDIEU, P. As regras da arte: gênese e estrutura do campo literário. São Paulo: Companhia das Letras, 1996.

BRAGA, J. L. Circuitos versus campos sociais. In: JANOTTI Jr., J.; MATTOS, M. Â.; JACKS, N. (Orgs). Mediação \& Midiatização. Salvador: Edufba; Brasília: Compós, 2012. p. 31-52.

COULDRY, N. Life with the media manifold: between freedom and subjection. In: KAMP, L. et al. (Eds.). Politics, civil society and participation: media and communications in a transforming environment. Bremen: Lumière, 2016. p. 25- 39.

COULDRY, N.; HEPP, A. The mediated construction of reality. Cambridge: Polity Press, 2017.

DALMONTE, E. F. Estudos culturais em comunicação: da tradição britânica à contribuição latino-americana. Idade Mídia, São Paulo, v. 1, n. 2, p. 67-90, nov. 2002.

FINNEMANN, N. O. Mediatization theory and digital media. Communications, Berlim, v. 36, n. 1, p. 67-89, 2011. DOI: https://doi.org/10.1515/comm.2011.004 GENTIKOW, B. The role of media in developing literacies and cultural techniques. Nordic Journal of Digital Literacy, Haia, v. 4, p. 35-52, 2015.

GIRARDI JR., L. Teoria das mediações e estudos culturais: convergências e perspectivas. Líbero, São Paulo, v. 12, n. 23, p. 117-127, jun. 2009.

. "Cultural techniques" e a materialidade da comunicação: contribuições para uma "digital literacy". In: ENCONTRO ANUAL DA COMPÓS. 26., 2017, São Paulo. Anais... São Paulo: Faculdade Cásper Líbero, 2017a.

. O estranho mundo da informação - e da materialidade - no campo da comunicação. Revista E-Compós, Brasília, v. 20, n. 1, p. 1-18, jan./abr. 2017b. DOI: http://dx.doi.org/10.30962/ec.v20i1.1296 jovem antropólogo, Gregory Bateson" (Martín-Barbero, 2009: 154). Martín-Barbero está se referindo, provavelmente, às Conferências Macy que foram um marco do pensamento

cibernético. Um pensamento que nunca teve uma boa acolhida no campo da comunicação.

21 "Por affordances de uma mídia, compreendemos as possibilidades de comunicação e interação que esta mídia proporciona a um usuário potencial. $\mathrm{O}$ usuário pode fazer ou não uso dessas affordances, e pode terminar tirando vantagem de algumas affordances que não foram antecipadas pelos desenvolvedores da mídia” (Hjarvard, 2015: 58). Gentikow (2015), por exemplo, resgata a noção de arquitetura da comunicação proposta por Holmes (2005). No caso das novas mídias, Manovich (2013: 15-16) destaca que esse tipo de problema também aparece de uma nova forma. Aqueles autores que se concentram na importância do entendimento do software e da materialidade dos meios estiveram envolvidos em projetos e práticas culturais que incluíam o ensino ou o desenvolvimento de programas ou linguagens de programação. Já os autores que não tiveram esse tipo de experiência tendem a praticamente ignorar o seu significado como forma cultural.

${ }^{22}$ Esses tensionamentos foram lançados nas notas de rodapé para que o pensamento de Martín-Barbero tivesse o destaque necessário. Sobre essa opção, ver: Waizbort (1997).

${ }^{23}$ Deslocando a noção de espaço de possíveis pensada por Bourdieu (1996).

${ }^{24}$ Esses questionamentos foram inspirados em algumas reflexões elaboradas pelo autor deste artigo ao tratar das cultural techniques e a sua relação com os estudos sobre a materialidade da comunicação (Girardi, 2017a). 
GOMES, I. M. M. Gênero televisivo como categoria cultural: um lugar no centro do mapa das mediações de Jesús Martín-Barbero. Revista Famecos, Porto Alegre, v. 18, n. 1, p. 111-130, jan./abr. 2011. DOI: http://dx.doi. org/10.15448/1980-3729.2011.1.8801

GUMBRECHT, H. U. Produção da presença: o que o sentido não consegue transmitir. Rio de Janeiro: Contraponto, 2010.

GUNKEL, D. J. Beyond mediation: thinking the computer otherwise. Interactions, Bristol, v. 1, n. 1, p. 53-70, 2009. DOI: https://doi.org/10.1386/iscc.1.1.53_1

HEPP, A. As configurações comunicativas de mundos midiatizados: pesquisa da midiatização na era da "mediação de tudo". MATRIZes, São Paulo, v. 8, n. 1, p. 45-64, jan./jun. 2014. DOI: http://dx.doi.org/10.11606/issn.19828160.v8i1p45-64

HJARVARD, S. Midiatização: teorizando a mídia como agente de mudança social e cultural. MATRIZes, São Paulo, v. 5, n. 2, p. 53-91, jan./jun. 2012. DOI: http://dx.doi.org/10.11606/issn.1982-8160.v5i2p53-91

Da mediação à midiatização: a institucionalização das novas mídias. Parágrafo, São Paulo, v. 2, n. 3 p. 51-62, jul./dez. 2015.

HOGGART, R. As utilizações da cultura. Lisboa: Presença, 1973.

HOLMES, D. Communication theory: media, technology and society. Londres: Sage, 2005.

JACKS, N. Tendências latino-americanas nos estudos de recepção. Famecos, Porto Alegre, n. 5, p. 44-49, nov. 1996. DOI: http://dx.doi. org/10.15448/1980-3729.1996.5.2946

LIVINGSTONE, S. On the mediation of everything: ICA presidential address 2008. Journal of Communication, Los Angeles, v. 59, n. 1, p. 1-18, 2009. DOI: http://dx.doi.org/10.1111/j.1460-2466.2008.01401.x

LOPES, M. I. V. Mediação e recepção. Algumas conexões teóricas e metodológicas nos estudos latino-americanos de comunicação. MATRIZes, São Paulo, v. 8, n. 1, p. 65-80, jan./jun. 2014. DOI: http://dx.doi.org/10.11606/ issn.1982-8160.v8i1p65-80

MACHADO, A. A televisão levada a sério. São Paulo: Editora Senac, 2000.

MACKAY, H. (Ed.). Consumption and everyday life. Londres: Sage, 1997.

MANOVICH, L. The language of new media. Cambridge (MA): MIT Press, 2001. . Software takes command. Nova Iorque: Bloomsbury Academic, 2013.

MARTÍN-BARBERO, J. América Latina e os anos recentes: o estudo da recepção em comunicação social. In: SOUZA, M. W. de (Org.). Sujeito, o lado oculto do receptor. São Paulo: Brasiliense, 1995. p. 39-68.

. Dos meios às mediações: comunicação, cultura e hegemonia. Rio de Janeiro, Editora UFRJ, 1997. 
- Oficio de cartógrafo: travesías latinoamericanas de la comunicación em la cultura. Cidade do México: Fondo de Cultura Económica, 2002.

. Pistas para entre-ver meios e mediações. In: Dos meios às mediações: comunicação, cultura e hegemonia. Rio de Janeiro: Editora UFRJ, 2003. p. 11-21.

. Tecnicidades, identidades, alteridades: mudanças e opacidades da comunicação no novo século. In: MORAES, D. (Org.). Sociedade midiatizada. Rio de Janeiro: Mauad, 2006. p. 51-79.

. Uma aventura epistemológica (entrevista à Maria Immacolata Vassalo de Lopes). MATRIZes, São Paulo, v. 2, n. 2, p. 143-162, 2009. DOI: http:// dx.doi.org/10.11606/issn.1982-8160.v2i2p143-162

MEYROWITZ, J. No sense of place: the impact of electronic media on social behavior. Nova Iorque: Oxford University Press, 1985.

MORLEY, D.; SILVERSTONE, R. Domestic communication - technologies and meanings. Media, Culture and Society, Londres. v. 12, n. 1, p. 31-55, 1990. DOI: https://doi.org/10.1177/016344390012001003

MÜLLER, A.; FELINTO, E. Medialidade: encontros entre os estudos literários e os estudos de mídia. Contracampo, Niterói, v. 19, p. 125-136, 2008. DOI: https://doi.org/10.22409/contracampo.v0i19.405

NOVAES, A. da S. João do Rio e seus cinematógrafos. Rio de Janeiro: Mauad, 2015.

OROZCO GÓMEZ, G. O telespectador frente à televisão. Uma exploração do processo de recepção televisiva. Communicare, São Paulo, v. 5, n. 1, p. 27-42, 2005.

. Comunicação social e mudança tecnológica: um cenário de múltiplos desordenamentos. In: MORAES, D. (Org.). Sociedade midiatizada. Rio de Janeiro: Mauad, 2006. p. 51-79.

RONSINI, V. V. M. A perspectiva das mediações de Jesús Martín-Barbero (ou como sujar as mãos na cozinha da pesquisa empírica de recepção). In: ENCONTRO DA COMPÓS, 19., 2010, Rio de Janeiro. Anais... Rio de Janeiro: Pontifícia Universidade Católica, 2010. p. 1-16. Disponível em: $<$ https://goo.gl/LVjdbW>.>. Acesso em: 27 abr. 2018.

SÁ, S. P. de. Explorações da noção de materialidade da comunicação. Contracampo, Niterói, n. 10-11, p. 31-44, 2004. Edição especial.

SCOLARI, C. A. From (new)media to (hyper)mediations. recovering Jesús MartínBarbero's mediation theory in the age of digital communication and cultural convergence. Information, Communication \& Society, Abingdon, v. 18, n. 9, p. 1092-1107, 2015. DOI: https://doi.org/10.1080/1369118X.2015.1018299 SIFUENTES, L.; ESCOSTEGUY, A. C. O mapa das mediações comunicativas da cultura: uma segunda onda na abordagem das mediações de Martín-Barbero? 
In: ENCONTRO ANUAL DA COMPÓS, 25., 2016, Goiânia. Anais... Goiânia: Universidade Federal de Goiás, 2016. p. 1-17. Disponível em: $<$ https://goo.gl/Q2zsAq>. Acesso em: 27 abr. 2018.

SIGNATES, L. Estudo sobre o conceito de mediação e sua validade como categoria de análise para os estudos de comunicação. In: SOUSA, M. W. de (Org.) Recepção mediática e espaço público. São Paulo: Paulinas, 2006. p. 55-79.

SILVA, G. Mediação \& midiatização: conexões epistemológicas. Pode o conceito reformulado de bios midiático conciliar mediações e midiatização? In: JANOTTI Jr., J.; MATTOS, M. Â.; JACKS, N. (Orgs). Mediação \& Midiatização. Salvador: Edufba; Brasília: Compós, 2012. p. 79-105.

TEMER, A. C. R. P.; TONDATO, M. P. A tradição dos estudos culturais na perspectiva das contribuições latino-americanas. Novos Olhares, São Paulo, v. 3, n. 2, p. 150-159, 2. sem. 2014.

VAZ, P. Mediação e tecnologia. Revista Famecos, Porto Alegre, n. 16, p. 45-59, dez. 2001. DOI: http://dx.doi.org/10.15448/1980-3729.2001.16.3137

WAIZBORT, L. Pequena sociologia da nota de rodapé. Novos Estudos Cebrap, São Paulo, n. 48, p. 183-186, jul. 1997.

WILLIAMS, R. Televisão: tecnologia e forma cultural. São Paulo: Boitempo; Belo Horizonte: PUCMinas, 2016.

Artigo recebido em 11 de agosto de 2017 e aprovado em 13 de abril de 2018. 